\title{
Transcervical resection of endometrium in women with menorrhagia
}

\author{
Adam L Magos, Ralf Baumann, Alexander C Turnbull
}

\begin{abstract}
As an alternative to hysterectomy 16 women with menorrhagia were treated with hysteroscopic transcervical resection of the endometrium with an unmodified urological resectoscope. Twelve patients requested total resection of the endometrial lining with the intention of producing amenorrhoea, and four chose partial resection and hypomenorrhoea. Surgery was completed successfully in 15; the remaining woman, who had an acutely retroflexed uterus, sustained a uterine perforation during insertion of the rigid hysteroscope. There were no important postoperative complications, and 13 patients were discharged from hospital the day after operation. Follow up for up to six months showed beneficial effects on the duration of menses and the subjective assessment of menstrual blood loss and pain in the treated women, six of them becoming amenorrhoeic after total resection. Hysteroscopy at three months in 13 patients showed fibrosis confined to the upper half of the uterine cavity. Endouterine biopsy specimens showed the presence of microscopic deposits of normal endometrium in 10 women.
\end{abstract}

Although these results are preliminary, transcervical resection of the endometrium may have an important role in managing this common complaint.

\section{Introduction}

Menorrhagia - that is, unacceptably heavy or prolonged loss of menstrual blood-is a common complaint of women during their reproductive years and an important cause of iron deficiency anaemia in up to a quarter of women. ${ }^{1}$ An increase in menstruation may be due to local causes such as endometrial polyps and fibroids or systemic factors such as hypothyroidism and bleeding disorders, but in most cases no obvious abnormality is found. ${ }^{2}$ Management traditionally relies on symptomatic relief with drugs or hysterectomy. ${ }^{3}$ Typically, women are treated conservatively initially but a large number ultimately undergo a major operation when drug treatment fails or unacceptable side effects develop. ${ }^{4}$ Poorly controlled menorrhagia has become the primary indication for hysterectomy, the most commonly performed major operation for women of reproductive age. ${ }^{5}$

Recently, a simpler operation for managing abnormal menstruation has been suggested-namely, endometrial destruction by surgical diathermy. In 1983 DeCherney and Polan reported on 11 women with intractable uterine bleeding resistant to medical treatment who were treated as emergencies with cautery to the entire endometrial surface with a cytoscope-resectoscope. ${ }^{6}$ DeCherney et al extended the

series to include a total of 21 cases in 1987. ' All but three of their patients had blood dyscrasias or were at extreme risk of complications of anaesthesia, and indeed three patients died within six months after the operation from their primary disease. None the less, during follow up of up to five years most survivors were either amenorrhoeic or had only slight spotting, with one requiring a second ablation.

These results are impressive, but their interpretation is subject to several important limitations: the studies were retrospective, uterine bleeding was not measured in any way before or after the operation, and concurrent drugs for conditions such as leukaemia and aplastic anaemia, which themselves may affect ovarian function and thus uterine bleeding, were not accounted for. As rightly pointed out by the authors, the efficacy of this treatment as an elective procedure in otherwise healthy patients remains to be determined. We report the results of our pilot prospective study of hysteroscopic transcervical resection of the endometrium as an alternative to hysterectomy in fit women with menorrhagia.

\section{Patients and methods}

Sixteen women were recruited from the gynaecological outpatient department at this hospital with complaints of unacceptably heavy and prolonged or frequent periods (table). In no case was the uterus larger than that seen in an eight week pregnancy, though two of the women had fibroids on clinical examination. All but four had undergone endometrial curettage or biopsy within the previous 12 months, when histological findings had been normal. The women were keen to avoid hysterectomy but appreciated that the proposed treatment might fail. Although relevant in only three cases, they were advised that the operation might not guarantee sterility.

Characteristics of 16 parous women ${ }^{\star}$ treated with transcervical resection of endometrium

\begin{tabular}{lc}
\hline \multicolumn{1}{c}{ Characteristic } & Mean (range) \\
\hline Age (years) & $42 \cdot 7(28-54)$ \\
Length of periods (days) & $11 \cdot 2(5-30)$ \\
Length of cycle (days) & $26 \cdot 8(14-30)$ \\
Duration of menstrual complaints (months) & $33 \cdot 9(4-72)$
\end{tabular}

${ }^{\star}$ In 14 women previous medical treatment had been unsuccessful.

At the time of operation eight of the women were taking drugs to control their menstrual loss; these were stopped postoperatively. Except in one patient taking danazol, no specific steps were taken to ensure a thin endometrium at the time of the operation by either hormonal manipulation or confining the procedure to the follicular phase of the ovarian cycle. Twelve of the women asked to be rendered amenorrhoeic - that is, to have total endometrial resection-and four preferred
Correspondence to: Mr Magos.

BrMed f 1989;298:1209-12 
to continue with light periods and to undergo partial resection.

General anaesthesia was used throughout with the patient in the lithotomy position with the head tilted down. The procedures were carried out with an unmodified urological resectoscope fitted with a cutting loop, a continuous irrigation and suction sheath (26 French gauge), and a $4 \mathrm{~mm}$ forward-oblique telescope (Karl Storz, Tuttlingen, West Germany). A mixed diathermy current of $100 \mathrm{~W}$ for cutting and $50 \mathrm{~W}$ for coagulation was used in most cases (Valleylab, United Kingdom). The uterine cavity was distended with $1.5 \%$ glycine solution at an insufflation pressure of $100 \mathrm{~mm} \mathrm{Hg}$ and suction pressure of $50 \mathrm{~mm} \mathrm{Hg}$, the fluid balance being carefully monitored.

The uterine cavity was first inspected for suspicious areas or focal lesions by video camera. Experience with different operative routines had shown that the optimum technique entailed systematic resection of the endometrium, starting in the cornual regions followed by the fundus, posterior wall, lateral walls, and, finally, anterior wall, the aim being to excise tissue to include $1-2 \mathrm{~mm}$ of myometrium. For total resection we continued into the upper half of the endocervical canal, whereas for partial resection a $0.5 \mathrm{~cm}$ cuff of endometrium was left immediately above the internal cervical os. Resected debris was removed by periodic curettage or with polyp forceps and was sent for histological examination. At the end of the procedure the new cavity was inspected, any residual endometrium resected, and any persistent bleeding points coagulated.

All patients received antibiotic prophylaxis at the start of the operation $(750 \mathrm{mg}$ cefuroxime intravenously). Laparoscopy was done only in two women who underwent sterilisation after the resection. Patients were discharged from hospital as soon as they felt well enough and reviewed after six weeks, three months, and, in some cases, six months.

Menstrual symptoms before and after the operation were assessed both retrospectively and prospectively. A menstrual calendar comprising vaginal bleeding, vaginal discharge, and lower abdominal pain was rated daily on a scale of $0-3(0=$ none, $1=$ mild, $2=$ moderate, $3=$ severe) for at least one menstrual cycle before the operation and during follow up. Outpatient hysteroscopy and endouterine biopsy were carried out three months after the operation in 13 of the patients.

\section{Results}

All but one of the operations were completed successfully, including in one case the resection of a $3 \mathrm{~cm}$ submucous fibroid along with endometrium. The exception was in a woman with an acutely retroverted and retroflexed uterus who sustained a small perforation in the anterior wall during insertion of the hysteroscope and required a small laparotomy, resection being abandoned as a result. In the 15 successful cases histological examination of the resected tissue showed normal endometrium with large fragments of underlying myometrium, including evidence of adenomyosis in three. The mean (range) duration of the operation was $41(20-100)$ minutes but $28(20-35)$ minutes for the last five resections. The mean volume of glycine required for irrigation was $7 \cdot 1(2 \cdot 3-20 \cdot 9)$ litres, the mean deficit at the end of operation being $523(200-1000) \mathrm{ml}$; previous sterilisation made little difference to this. Clinical estimates of blood loss during the operation ranged between 100 and $300 \mathrm{ml}$. The only postoperative complication was low grade fever in one case, which resolved spontaneously within 24 hours. Thirteen patients were discharged from hospital the day after the operation, the remaining three staying two days.
Bleeding immediately after the operation was rarely heavy and persisted longer than 10 days in only two cases (range 1-28 days). This was followed by an inoffensive vaginal discharge for a mean (range) of $17 \cdot 5$ (5-34) days. Overall, the women were able to return to normal everyday activities after a mean of 1.9 $(0 \cdot 5-4 \cdot 0)$ weeks; 10 of the 11 who worked returned to their occupation after a mean of $2 \cdot 2(1-3)$ weeks.

Six of the 11 women who underwent total resection became amenorrhoeic during follow up of up to six months. Of the remaining five, one had only a single episode of bleeding a few weeks after the operation and four reported regular but shorter and lighter periods. Similarly, partial resection was associated with lighter menstruation of shorter duration. Although painful periods were not a major complaint of any of the women before resection, pain improved with treatment, and four of the eight women who continued to menstruate had painless periods. Analysis of the daily ratings from the menstrual calendars confirmed these reports, the duration of bleeding, the amount of blood loss, and menstrual pain all being improved throughout follow up after both total and partial resection (figs 1 and 2). For those who continued to bleed improvements in menstruation seemed to be related not only to shortening of the episodes of monthly bleeding but also to a reduction in the mean daily loss.

Hysteroscopic examination in 13 cases three months after the operation showed that the uterine cavity had not been obliterated completely in any of the cases. Pale, translucent, fibrous looking tissue was generally restricted to the upper portion of the uterine cavity or fundus sufficient to obscure one or both tubal ostia in nine cases, menstrual bleeding preventing proper assessment of the cornual regions in one patient. A narrow ring of normal looking endometrium was present above the internal cervical os in the four women who underwent partial resection, but it was difficult to identify endometrium elsewhere hysteroscopically. Endometrium in endouterine biopsy specimens was histologically normal in the group who had partial resections, but otherwise there was no clear relation between histological findings and patterns of menstrual bleeding postoperatively, microscopic deposits of endometrium being found in three out of five women who were amenorrhoeic and seven out of eight who were not. Histiocytes and mutlinucleate giant cells of a foreign body type were identified in three samples and myometrium in one; there was no evidence of squamous metaplasia in any of the biopsy specimens.

Of the 15 women who had resection, 12 were satisfied with the results of intervention and did not resume their drug treatment for menorrhagia. The remaining three, two of whom were the first patients we treated, were disappointed despite improvements in their periods and two requested hysterectomy. One of them, the first woman treated by total endometrial resection, underwent vaginal hysterectomy four months after her resection. Macroscopic examination of a specimen taken at operation showed that the uterine cavity was lined by a greyish pink, slightly translucent tissue $1 \mathrm{~mm}$ in average thickness with obstruction of the cavity in several places. Histological sections showed thin endometrium throughout with occasional points of granulation tissue.

\section{Discussion}

The concept of destroying endometrium to manage abnormal menstruation is not new. The intrauterine applications of cytotoxic chemicals and cryocautery were briefly reported almost 20 years ago but have not been developed further. ${ }^{89}$ More recently, hystero- 

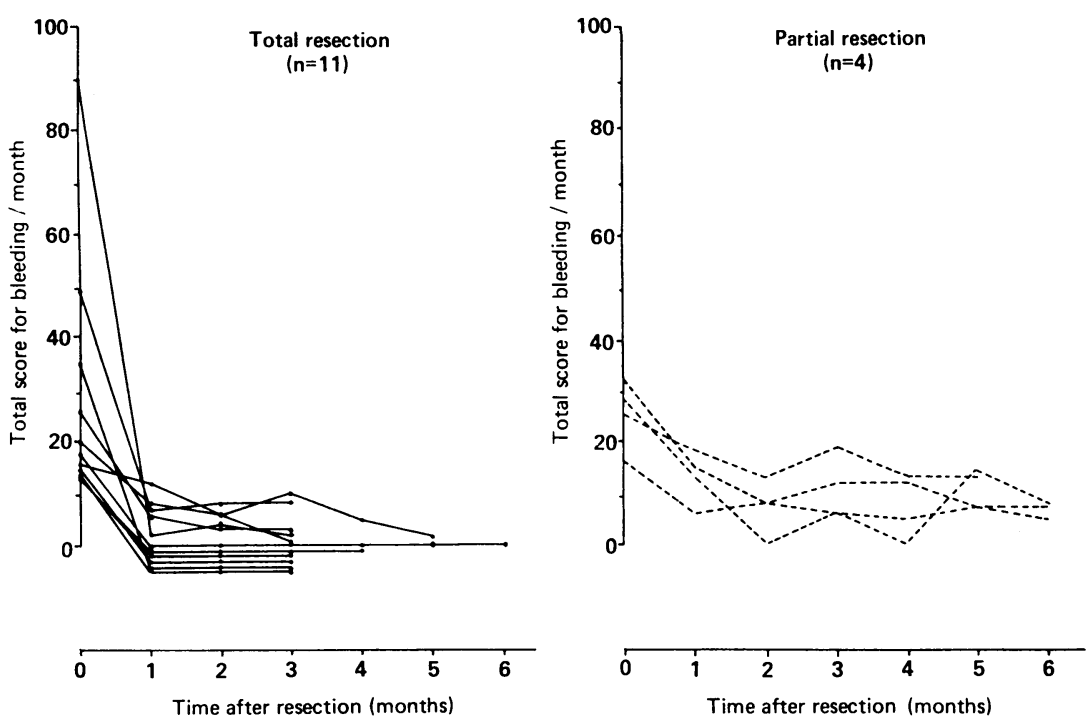

FIG $1-$ Effect of total and partial endometrial resection on total amount of menstrual bleeding each month. Blood loss was scored daily on scale of 0 to 3 (none to heavy)
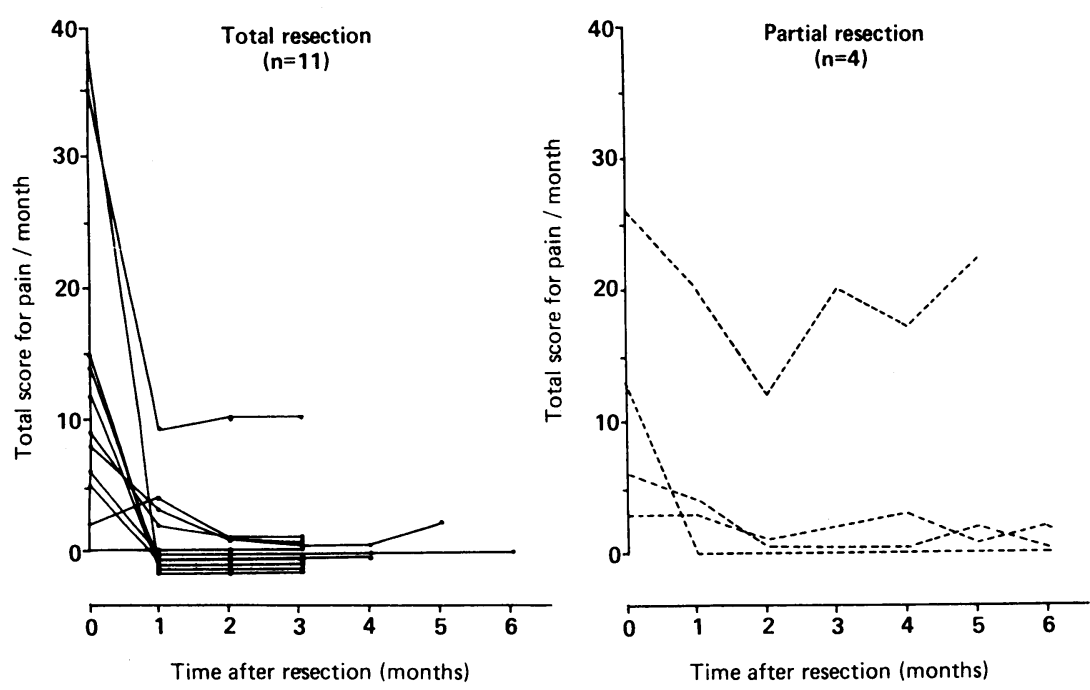

FIG 2-Effect of total and partial endometrial resection on total amount of menstrual pain each month. Pain was scored daily on score of 0 to 3 (none to severe)

scopic laser ablation of the endometrium has been described, several studies confirming the efficacy of this treatment, which was first reported by Goldrath $e t$ al in $1981 . .^{10}$ Although attractive and potentially suitable for treating outpatients, ${ }^{11}$ this approach requires an expensive neodymium-yttrium aluminium garnet laser unit, does not provide a specimen for histological examination, and seems to be slower. ${ }^{12}$

In contrast, the urological resectoscope is fairly cheap and widely available in hospitals. In addition to being used to stem uncontrollable uterine haemorrhage it has been adapted for other types of intrauterine surgery, such as removal of submucous fibroids, septa, and even benign mesodermal tumours through the vagina..$^{13-15}$ We have shown that healthy women with heavy, prolonged, or frequent periods may also be candidates for this type of operation as an alternative to hysterectomy, the endometrium being completely or partially excised with a cutting diathermy loop. There was a consistent and considerable reduction in the duration of menstrual bleeding, the amount of flow per cycle, and period pains, in over half the women after total resection. The results of laser ablation seem to be comparable. ${ }^{16}$ Unpublished reports from Europe have suggested similar effects of partial resection on menstrual flow to those obtained in our study ( $J$ Hamou, first international gynaecological endoscopy meeting, Oxford, 1988).

The menstrual benefits of endometrial resection are unlikely to be merely a "curettage" effect as conventional dilatation and curettage is followed by a reduction in menstrual blood loss in only the first period and, typically, bleeding during the second period is increased compared with the overall loss. ${ }^{17}$ In contrast, even in women who did not become amenorrhoeic resection seemed to be followed by a progressive decrease in the menses at least over the first six months. Whether this effect will be permanent remains to be seen, but despite its limitations the work of DeCherney et al suggests that this may be the case.? Although the endometrium has great powers of regeneration after surface necrosis, complete excision or destruction of the basal layer seems to prevent future growth. ${ }^{18}$

As to why partial resection lessens menstrual blood loss, we must assume that this is related to the overall reduction in endometrial surface area. Although in untreated women complaining of menorrhagia objective measures of menstrual blood loss do not correlate with endometrial surface area, ${ }^{2}$ this is unlikely to apply in extreme cases of endometrial denudation. The improvement in menstruation, even after total resection, is certainly not explained solely by the production of an iatrogenic Asherman's syndrome (amenorrhoea traumatica) with its associated intrauterine adhesions and conglutination of the opposing uterine walls ${ }^{19}$ as in most cases the cavity of the uterus remains essentially intact except for the fundal region.

In 1985,18600 hysterectomies were performed in England for menstrual disorders, ${ }^{20}$ with a recent audit from the United Kingdom suggesting that no abnormality is found in over half of such operative specimens. ${ }^{21}$ Although the mortality after hysterectomy for benign disorders has been reported as only 6.0 per $10000,{ }^{22}$ the short term morbidity rate in one large series was as high as 24.5 and 42.8 per 100 for vaginal and abdominal hysterectomies respectively..$^{23}$ At least as worrying are the potential long term effects of hysterectomy, including premature ovarian failure, ${ }^{24}$ increased risk of cardiovascular disease, ${ }^{25}$ and possibly psychosexual dysfunction. ${ }^{26}$ These statistics and the financial and social implications of a lesser operation seem to make endometrial destruction, whether by electrocautery or laser, an attractive alternative to hysterectomy and arguably even long term drug treatment in women who have completed their families.

Our results are preliminary, and the short and long term efficacy of hysteroscopic endometrial resection in reducing menstrual blood loss remains to be proved by objective techniques. The dangers of malignant change within the uterine cavity ${ }^{72}$ must be assessed, though the theoretical basis for a fear that equates the effects of electrocautery and laser with that of ionising radiation is unconvincing. ${ }^{27}$ More immediately, the operative risks must be documented on a large series of patients as resection may result in haemorrhage, infection, and uterine perforation with consequent bowel trauma. As in our study, a rigid hysteroscope may prove to be unsuitable when the uterus is acutely anteflexed or retroflexed, and a flexible instrument with a laser attachment would be preferable under these conditions. As with the conceptually similar procedure of transurethral resection of the prostate the risks of fluid overload and haemolysis from the distension medium must also be guarded against; dextran 70 is a safer alternative to $1.5 \%$ glycine in this respect but has the dual disadvantages of high viscosity and possible anaphylaxis. ${ }^{28}$ Intrauterine surgery is a skilled technique, and much valuable knowledge can be gained from urologists, who have been performing a similar procedure in men for over 40 years.

We thank Mr Peter Rimmer, of Rimmer Brothers, 
London, for lending us the equipment to perform resections and outpatient hysteroscopy; Dr Elizabeth Horak, clinical lecturer in the Nuffield department of pathology, Oxford, for performing the histological examinations; Mr J C Smith, consultant urologist, Oxford, for his invaluable advice and enthusiastic support of our work; and the Wellington Foundation for its financial help to ALM to attend the hysteroscopy course and workshop at the Jan Palfjin Hospital in Antwerp, Belgium.

1 Rybo G. Clinical and experimental studies on menstrual blood loss. Acta Obste Gynecol Scand 1966;45(suppl): 1-23.

2 Chimbira TH, Anderson ABM. Turnbull AC. Relation between measured menstrual blood loss and patien's subjective assessment of loss, duration of derigent bleeding, number of sanitary towels used, uterine

Rees MP. Menorrhagia - an algorithm. Br Med f 1987;294:759-62.

3 Rees MP. Menorrhagia - an algorithm. Br Med F 1987;294:759-62.

5 Dicker RC, Scally MJ, Greenspan JR, et al. Hysterectomy among women of reproductive age. Trends in the United States, 1970-1978. JAMA 1982;248:
reter reprodict

6 DeCherney AH, Polan ML. Hysteroscopic management of intrauterine lesions and intractable uterine bleeding. Obstet Gynecol 1983;61:392-7.

7 DeCherney AH, Diamond MP, Lavy G, Polan ML. Endometrial ablation fo intractable uterine bleeding: hysteroscopic resection. Obstet Gynecol 1987;70:668-70

8 Zipper J, Medel M, Pastene L, Rivera M. Intrauterine instillation of chemical cytotoxic agents for tubal sterilisation and treatment of functional metrorrhagias. Int $\mathcal{F}$ Fertil 1969;14:280-8.

9 Droegemueller W, Makowski E, Macsalka R. Destruction of the endometrium by cryosurgery. Am $\mathcal{F}$ Obstet Gynecol 1971;110:467-9.

10 Goldrath MH, Fuller TA, Segal S. Laser photovaporisation of endometrium for the treatment of menorrhagia. Am $\mathcal{F}$ Obstet Gynecol 1981;140:14-9.

11 Cornier E. Traitement hysterofibroscopique ambulatoire des metrorragies rebelles par laser Nd:YAG. I Gynecol Obstet Biol Reprod (Paris) 1986;15: 661.4

12 Baggish MS, Baltoyannis P. New techniques for laser ablation in high-risk patients. Am $\mathcal{F}$ Obstet Gynecol 1988;159:287-92.
13 Neuwirth RS. A new technique for and additional experience with hysteroscopic resection of submucous fibroids. Am $f$ Obstet Gymecol 1978;131:91-4

14 Haning RV, Harkins PG, Uehling DT. Preservation of fertility by transcervical resection of a benign mesodermal uterine tumor with a resectoscope and ection of a benign mesoderril

15 DeCherney AN, Russell JB, Graebe RA, Polan ML. Resectoscopic management of mullerian fusion defects. Fertil Steril 1986;45:726-8.

16 Loffer FD. Laser ablation of the endometrium. Obstet Gynecol Clin North Am 988;15:77-89.

17 Haynes PJ, Hodgson H, Anderson ABM, Turnbull AC. Measurement of menstrual blood loss in patients complaining of menorrhagia. $\mathrm{Br}$ f Obstet Gynaecol 1977;84:763-8.

18 Schenker JG, Polishuk WZ. Regeneration of rabbit endometrium following intrauterine instillation of chemical agents. Gynecol Invest 1973;4:1-13.

19 Asherman JG. Traumatic intra-uterine adhesions. Fournal of Obstetrics and Gynaecology of the British Empire 1950;57:892-903.

20 Department of Health and Social Security and Office of Population Censuses and Surveys. Hospital in-patient enquiry, 1985. London: HMSO, 1985: table P1. (MB No 4.)

21 Grant JM, Hussein IY. An audit of abdominal hysterectomy over a decade in a district hospital. Br f Obstet Gynaecol 1984;91:73-7.

22 Wingo PA, Huezo CM, Rubin GL, Ory HW, Peterson HB. The mortality risk associated with hysterectomy. Am $\mathcal{O}$ Obstet Gynecol 1985;152:803-8.

23 Dicker RC, Greenspan JR, Strauss LT, et al. Complications of abdominal and vaginal hysterectomy among women of reproductive age in the United States. Am J Obstet Gynecol 1982;144:841-8.

24 Siddle N, Sarrel $P$, Whitehead MI. The effect of hysterectomy on the age of ovarian failure: identification of a subgroup of women with premature loss of ovarian function and literature review. Fertil Steril 1987;47:94-100.

25 Centerwall BS. Premenopausal hysterectomy and cardiovascular disease. $A m \mathcal{F}$ Obstet Gynecol 1981;139:58-61.

26 Richards DH. A post-hysterectomy syndrome. Lancet 1974;ii:983-5.

27 Baggish MS, Woodruff JD. The occurrence of squamous epithelium in the endometrium. Obstet Gynecol Surv 1967;22:69-115.

28 Rioux JE. Methods of uterine distension. In: Seigler AL, Lindemann HJ, eds. Hysteroscopy: principles and practice. Philadelphia: Lippincott, 1984:37-40.

(Accepted 28 March 1989)
Epidemiology and Public Health Research Unit, University of Surrey, Guildford, Surrey GU2 5XH

P Yuen, MSC, research fellow R Balarajan, FFCM, director

Correspondence to:

Dr Balarajan.

\title{
Unemployment and patterns of consultation with the general practitioner
}

\author{
P Yuen, R Balarajan
}

\begin{abstract}
The relation between unemployment and consultations with the general practitioner was investigated among 13275 economically active men aged 18-64 by using the British general household surveys. Men who were unemployed but seeking work consulted with doctors significantly more (odds ratio $1.83 ; 95 \%$ confidence interval 1.61 to 2.09 ) than those in employment, the highest consultation rate being among those who had been out of work for five years or more (odds ratio $2 \cdot 12 ; 95 \%$ confidence interval $1 \cdot 12$ to 3.78 ). The high consultation rates persisted even after adjustment for self reported longstanding illness (odds ratio 1.53; 95\% confidence interval 1.34 to $1 \cdot 76)$.
\end{abstract}

These findings suggest that in areas with high unemployment general practitioner workload is likely to be high.

\section{Introduction}

Unemployment in Britain rose rapidly in the early 1980 s, a fivefold increase having occurred over 12 years. ${ }^{1}$ This increase focused a great deal of interest on the health of the unemployed. In England and Wales excess mortality among unemployed men seeking work has been shown by using data from the Office of Population Censuses and Surveys' longitudinal study, the excess mortality persisting even when socioeconomic factors such as social class and housing tenure were taken into account. ${ }^{23} \mathrm{~A}$ follow up study in Denmark also disclosed significantly higher death rates among the unemployed. ${ }^{4}$ Nevertheless, little published research has been made available on the levels and patterns of morbidity among those out of work. Small scale observational studies have reported high levels of stress and mental disorders in those unemployed and those under threat of becoming unemployed. ${ }^{56}$ Most of these studies were not representative, being either too small or localised, with the exception of the recent Canada health survey. ${ }^{7}$ In that study substantial differences in health between the employed and unemployed were found, people out of work having significantly higher levels of psychological stress and ill health.

We have analysed data from the British general household surveys to investigate the health of the unemployed as it relates to consultation with a general practitioner.

\section{Subjects and methods}

The general household survey is a yearly sample survey conducted by the Office of Population Censuses and Surveys, providing information on a wide range of topics such as employment, health, housing, and education in some 30000 people from 12000 private households. The 1983 and 1984 surveys $^{89}$ were combined and used in this analysis to increase the sample size. We defined as unemployed people who were not working but were seeking work or waiting to take up a job and included in our study only economically active men aged 18 to 64 . Full time students and those who were permanently sick and unable to work were excluded. Duration of unemployment was further examined in five categories (table I).

To allow for possible confounding we also obtained information on age, housing tenure, occupation (most 